\title{
Memory-enhancing effect of aspirin is mediated through opioid system modulation in an $\mathrm{AlCl}_{3}$-induced neurotoxicity mouse model
}

\author{
SAIMA RIZWAN $^{1 *}$, AYESHA IDREES $^{1 *}$, MUHAMMAD ASHRAF $^{2}$ and TOUQEER AHMED ${ }^{1}$ \\ ${ }^{1}$ Neurobiology Laboratory, Department of Healthcare Biotechnology and ${ }^{2}$ Department of Plant Biotechnology, \\ Atta-ur-Rahman School of Applied Biosciences, National University of Sciences and Technology, \\ Sector H-12, Islamabad 44000, Pakistan
}

Received March 12, 2015; Accepted November 25, 2015

DOI: $10.3892 / \mathrm{etm} .2016 .3147$

\begin{abstract}
Neurodegenerative disorders such as Alzheimer's disease (AD) are multifaceted and there are currently a limited number of therapeutic strategies available to treat them. Aspirin is known to act on multiple therapeutic targets and is a successful anti-inflammatory agent in various tissues. The present study aimed to ascertain the performance of aspirin when employed as a therapeutic agent to treat neurodegeneration on novel targets, including opioid system genes, in an $\mathrm{AlCl}_{3}$-induced neurotoxicity mouse model. The effects of two doses of aspirin (5 and $20 \mathrm{mg} / \mathrm{kg}$ aspirin for 12 days) were investigated in an $\mathrm{AlCl}_{3}$-induced neurotoxicity mouse model (150 mg/kg $\mathrm{AlCl}_{3}$ for 12 days). Neurological improvements were assessed through different behavioral tests and the effects of aspirin on opioid system gene expression levels were assessed by reverse transcription-polymerase chain reaction. Both doses resulted in improvements in cognitive behavior. A $5 \mathrm{mg} / \mathrm{kg}$ dose of aspirin was revealed to be effective for spatial memory improvement $(7.14 \pm 0.84 \mathrm{sec})$, whilst a $20 \mathrm{mg} / \mathrm{kg}$ dose was superior for improving extinction learning $(7.63 \pm 4.04 \%)$. Aspirin $(5 \mathrm{mg} / \mathrm{kg})$ also significantly improved contextual memory $(48.05 \pm 10.6 \%)$ when compared with the $\mathrm{AlCl}_{3}$-treated group $(1.49 \pm 0.62 \% ; \mathrm{P}<0.001)$. Aspirin was also observed to significantly decrease $\delta$-opioid receptor expression in the cortex $(1.09 \pm 0.08$ and $1.27 \pm 0.08$, respectively) at both doses (5 and $20 \mathrm{mg} / \mathrm{kg}$ ) when compared with the $\mathrm{AlCl}_{3}$-treated group $(3.69 \pm 1.43 ; \mathrm{P}<0.05)$. Furthermore, aspirin at $5 \mathrm{mg} / \mathrm{kg}$ significantly reduced expression of prodynorphin in the cortex $(0.57 \pm 0.20)$ when compared with the $\mathrm{AlCl}_{3}$-treated group
\end{abstract}

Correspondence to: Dr Touqeer Ahmed, Neurobiology Laboratory, Department of Healthcare Biotechnology, Atta-ur-Rahman School of Applied Biosciences, National University of Sciences and Technology, Sector H-12, Islamabad 44000, Pakistan

E-mail: touqeer.aahmed@gmail.com; touqeer.ahmed@asab.nust.edu.pk

*Contributed equally

Key words: hippocampus, amygdala, $\delta$ opioid receptors, $\kappa$ opioid receptors, social preference, fear memory
$(1.95 \pm 0.84 ; \mathrm{P}<0.05)$. Notably, the effect of aspirin was significant in the cortex but not in the hippocampus. In summary, aspirin was effective in ameliorating the AD-like symptoms via the modulation of opioid systems. However, additional studies are required to determine the long term effects of aspirin on such conditions.

\section{Introduction}

The worldwide prevalence of dementia was 35.6 million in 2010 , with $58 \%$ of patients with dementia residing in countries of low or middle income (1). There are multiple causes associated with neurodegenerative diseases. Certain chemicals, including trace elements and metals, such as aluminium, copper, arsenic, mercury, lead and manganese, are neurotoxicant in high amount (2). In particular, aluminium is known for its neurotoxicant properties (3). Aluminium exposure through the oral route results in an accumulation within the body, particularly the brain $(4,5)$, causing a number of neurological disorders, including Alzheimer's disease (AD) (6). An epidemiological study supported the hypothesis of an association between chronic exposure to aluminium and the incidence of AD (7); however, this has yet to be elucidated. Additionally it has been revealed that levels of aluminium are elevated in the brains of patients with AD (8).

Nonsteroidal anti-inflammatory drugs (NSAIDs) are used to treat inflammation (9). NSAIDs primarily inhibit cyclooxygenases (COXs), and their role in the modulation of ion channels and nociceptors is well established (9). NSAIDs have been shown to decrease the risk of AD by $50 \%(10,11)$. Amongst the NSAIDs, aspirin (acetylsalicylic acid) is one of the most prominently used in medical practice. Aspirin is widely utilized for the treatment of vascular dementia and possesses potential as a therapeutic agent in neurodegenerative disorders $(12,13)$. Aspirin has been revealed to target pathological pathways in neurodegenerative disorders $(14,15)$, however, the exact mechanisms of action of aspirin have yet to be elucidated. Furthermore, there is limited data concerning the therapeutic efficacy of aspirin on the opioid system in AD.

Endogenous opioid neuropeptides (including dynorphins and enkephalins) and their receptors ( $\kappa$ and $\delta$ ) are important in modulating sensory, motivational, emotional, and cognitive function and addictive behaviors (16-18). Different types of 
opioid receptor (including $\mu, \delta$ and $\kappa$ ) have unique patterns of distribution within the human brain, typically displaying a high density in gray matter, and are preferentially found in limbic and limbic-associated brain structures $(19,20)$. The distribution of opioid receptors in these areas have a critical role in higher cognitive and emotional behaviors. These effects are hypothesized to be mediated by modulating neuronal firing, and the release of neurotransmitters and hormones $(21,22)$.

Dynorphins, for example dynorphin A (Dyn A), Dyn B and $\alpha$-neoendorphin, are derived from the long precursor prodynorphin (Pdyn), and modulate cognition through $\kappa$-opioid receptors (KOR) (23-25). Enkephalins, namely met- and leu-enkephalins, are produced by the proteolytic cleavage of pre-proenkephalin (Penk), which is responsible for the modulation of learning and memory (26), synaptic plasticity (27), and emotional behaviors (28).

Peptide (including somatostatin, corticotrophin releasing factor and opioid peptide) neurotransmission is vital for normal cognitive functions; however, it is impaired in neurodegeneration (29). There is strong evidence to suggest that alterations in the level of neuropeptides may be associated with neuropathology $(30,31)$; however, the exact roles of the majority of peptides involved in neurodegeneration remains unclear.

The opioid system is hypothesized to have an association with neuropathology, making it an attractive therapeutic target in neurodegeneration. Thus, the present study aimed to assess the performance of a frequently used multi-targeting therapeutic agent, aspirin, known for its effectiveness against such novel targets, for the treatment of neurodegeneration induced by $\mathrm{AlCl}_{3}$. The results observed were promising in favour of the use of aspirin.

\section{Materials and methods}

Drugs and chemicals. $\mathrm{AlCl}_{3}$ hexahydrate (cat no. AL0770) was purchased from Scharlab, S.L. (Barcelona, Spain), aspirin (batch no. 3083) was purchased from the Reckitt Benckiser Group plc, (Karachi, Pakistan) and TRIzol was purchased from Invitrogen (Thermo Fisher Scientific, Waltham, MA, USA). Chemicals used for polymerase chain reaction (PCR), including $\mathrm{MgCl}_{2}$, dNTPs and Taq polymerase (EP0402), were purchased from Fermentas (Thermo Fisher Scientific, Inc.).

Animals. All experiments performed complied with the Guide for the Care and Use of Laboratory Animals (32). The protocol was approved by the Internal Review Board, Atta-ur-Rahman School of Applied Biosciences, National University of Sciences and Technology (Islamabad, Pakistan). Male BALB/c mice (age, 3-4 months; weight range, 27-45 g) were purchased from the National Institute of Health (Islamabad, Pakistan). Mice were housed in a controlled environment (temperature, $25 \pm 2^{\circ} \mathrm{C}$; natural light and dark cycle), and were provided with tap water and a standard diet. A total of 40 mice were used in this study ( $n=7-12$ per group) and each mouse was assigned a unique identity.

Animal model for $\mathrm{AlCl}_{3}$-induced neurotoxicity, study design and aspirin treatment plan. $\mathrm{An} \mathrm{AlCl}_{3}$-induced neurotoxicity mouse model was developed as previously reported by our laboratory (33). Animals were divided into four groups, termed: i) Control group, received normal saline through intraperitoneal (IP) injection for 12 days; ii) $\mathrm{AlCl}_{3}$-treated group, received $150 \mathrm{mg} / \mathrm{kg} \mathrm{AlCl}$ through IP injection according to the weight of mice every day for 12 days; iii) aspirin $40 \mathrm{ppm}$ group, received a $5 \mathrm{mg} / \mathrm{kg}$ dose of aspirin (40 ppm mixed in feed for 12 days; and iv) aspirin 160 ppm group, received a $20 \mathrm{mg} / \mathrm{kg}$ dose of aspirin (160 ppm mixed in feed for 12 days). The required dose $/ \mathrm{kg}$ of aspirin was delivered by adding aspirin into the feed. The ppms of aspirin were calculated based on the feed consumption of mice prior to the commencement of the study.

Behavior testing. Behavior tests were performed on day 12 of treatment between 12:00 and 6:00 p.m. with minimal human interference. All tests were recorded using a video camera (Sony Corporation, Tokyo, Japan)and analyzed offline. The mice were transferred to the testing room $30 \mathrm{~min}$ prior to the first test.

\section{Spatial reference memory}

The Morris water maze test protocol was performed as previously described $(33,34)$, with slight modifications. In this test, a $90-\mathrm{cm}$ diameter pool containing a hidden platform submerged in the south western quadrant $1 \mathrm{~cm}$ below the surface of water was included. The water pool was made opaque and the temperature of the water was maintained at $20 \pm 2^{\circ} \mathrm{C}$. The room contained high contrast spatial cues, including black geometric shapes against a white wall background.

Procedure. The test commenced on the seventh day of treatment and trials were conducted each day for the next 6 days. Mice underwent five trials each day with an inter-trial interval of $10 \mathrm{~min}$. The platform position remained consistent throughout the trials while mouse starting direction differed in each trial. Maximum trial duration was $60 \mathrm{sec}$, and the time taken by the mouse to reach the platform was recorded and plotted as escape latency. In the event of a mouse failing to locate the platform within the duration, the mouse was guided to the platform and escape latency (sec) for that trial was taken as $60 \mathrm{sec}$.

Test trial. On the sixth day of the test, animals were assessed for their memory by performing a test trial. During test trial, the platform was removed, and the time spent by the mouse within the platform quadrant was recorded and plotted as platform exploration time (sec).

Social interaction behavior. The procedure was performed as described previously (33). The apparatus consisted of an iron box $(40 \times 40 \times 40 \mathrm{~cm})$ and two identical small cages placed within the box. The treated mice were termed test subject, and two further mice were termed mouse A and B, respectively. Mice A and B were of the same background with respect to age, gender and weight, and had not had any prior contact with the test subject mice.

Session I: Social affiliation test. Following a habituation period of $5 \mathrm{~min}$ inside the box, the cage containing mouse $\mathrm{A}$ was placed on one side of the box and an empty cage was placed on the other side. The test subject was allowed to explore both cages for $10 \mathrm{~min}$ and the time spent with the empty cage (defined as the test subject facing the cage, with a distance of $<1 \mathrm{~cm}$ between the test subject and the cage) and 
mouse A were recorded. The percent interaction time (\%) was calculated by the dividing the time spent exploring by the total time for mouse A and the empty cage.

Session II: Social novelty preference test. In this session, the empty cage was replaced with mouse B and mouse A remained unchanged. The test subject was allowed to explore for $10 \mathrm{~min}$ and the interaction time (\%) was calculated by dividing the percent of time spent exploring with mouse A or mouse $\mathrm{B}$ by the total time.

Discrimination index (DI). DIs for sessions I and II were calculated using the following formulas:

\section{Session I}

Time spent with mouse A

$$
\mathrm{DI}=
$$

Time spent with mouse A + time spent with empty cage

\section{Session II}

Time spent with mouse B

$$
\mathrm{DI}=\frac{}{\text { Time spent with mouse } \mathrm{A}+\text { time spent with mouse } \mathrm{B}}
$$

Nesting behavior. The organizational behavior of the mice was assessed through the nesting test, following a previously described protocol (35). The test mice were kept in individual cages, containing a nestlet (a compressed cotton batting of weight $2 \mathrm{~g}$ ), $1 \mathrm{~h}$ before the dark phase started. The following morning, the mice were scored between 1 and 5 dependent on the utilization of cotton and the quality of the nest, as follows: 1 , cotton not noticeably touched; 2 , cotton partially torn up; 3 , cotton mostly shredded with no identifiable location; 4 , identifiable nest but flat; 5 , perfect or nearly perfect nest.

\section{Fear learning and memory testing}

Fear conditioning. Fear conditioning protocol was performed as previously described (36), with slight modifications. The system was loaded with an audio speaker to provide a tone [conditioned stimulus (CS)] of 3,000 Hz, $80 \mathrm{~dB}$ intensity and $30 \mathrm{sec}$ duration. A foot shock [US (unconditioned stimulus)] was delivered at the end of the CS for $1 \mathrm{sec}$ with $0.5 \mathrm{~mA}$ intensity. The test trial consisted of $2 \mathrm{~min}$ habituation followed by five CS-US pairings, each with 2 min intervals. Freezing was assessed as an index of fear response during the $30 \mathrm{sec}$ of CS.

Contextual fear. Context-dependent fear memory was measured $24 \mathrm{~h}$ after fear conditioning in the same box in the absence of CS or US. The freezing response to the context was measured for $5 \mathrm{~min}$.

Fear extinction. Fear extinction was performed in a different context to that of the fear conditioning chamber. The box utilized for this experiment was made of plastic. Following 7 min of habituation in the chamber, animals were exposed to $20 \mathrm{CS}$ trials with each trial lasting for $30 \mathrm{sec}$ and followed by a $30 \mathrm{sec}$ interval. Freezing response was measured during CS trials and plotted.

Gene expression analysis. Gene expression analysis was performed in accordance with the previously described protocol (37). After completion of the behavior assessments on day 12 , animals were anesthetized with diethyl ether (676845;
Sigma-Aldrich, St. Louis, MO, USA) and sacrificed by decapitation in order to extract the cortex and hippocampus. RNA was extracted using TRIzol reagent, according to the manufacturer's protocol. From each sample, $1 \mu \mathrm{g}$ extracted RNA was selected and reverse transcribed by reverse transcriptase (Fermentas; Thermo Fisher Scientific, Inc.) to produce cDNA (40 $\mu \mathrm{l})$. cDNA was used for targeted gene amplification by PCR using gene-specific primers (Eurofins Genomics GmbH, Ebersberg, Germany) with different annealing temperatures, as indicated in Table I. The thermal cycling conditions were as follows: Initial denaturation at $95^{\circ} \mathrm{C}$ for $5 \mathrm{~min}$ followed by denaturation at $94^{\circ} \mathrm{C}$ for $30 \mathrm{sec}$, annealing for $30 \mathrm{sec}$ and an initial extension at $72^{\circ} \mathrm{C}$ for $30 \mathrm{sec}$. This cycle was repeated for a specific number of times at specific annealing temperatures, as detailed in Table I. The final extension was performed at $72^{\circ} \mathrm{C}$ for $10 \mathrm{~min}$. Actin was used as a housekeeping gene and to normalize gene expression. PCR amplified products were run on $2 \%$ agarose gel (Bio Basic, Inc., Markham, ON, Canada) and visualized by ethidium bromide staining (E7637; Sigma-Aldrich). The gel images of PCR product bands were captured and saved using a Dolphin-Doc Plus gel imaging system (1141004; Weltec Corporation, Sparks, NV, USA). Each PCR product band was quantified for densitometry using ImageJ software (National Institutes of Health, Bethesda, MO, USA; http://rsbweb.nih.gov/ij/).

Statistical analysis. Results were analyzed statistically using GraphPad Prism software, version 5.0 (GraphPad Software, Inc., San Diego, CA, USA). For statistical analysis Bonferroni multiple comparison test was applied. $\mathrm{P}<0.05$ was considered to indicate a statistically significant difference. Data are expressed as the mean \pm standard error of the mean, where $n$ indicates the number of animals/observations.

\section{Results}

Aspirin enhances spatial reference learning and memory in $\mathrm{AlCl}_{3}$-treated mice. Aspirin was investigated in order to determine its involvement in spatial reference memory through the use of the Morris water maze task. The $\mathrm{AlCl}_{3}$-treated group displayed impairments in the spatial reference memory test and learnt at a reduced pace (Fig. 1A), as demonstrated by the increased escape latency in the final 3 days $(16.22 \pm 1.49 \mathrm{sec})$ when compared with the control group $(7.53 \pm 1.21 \mathrm{sec}$; $\mathrm{P}<0.05$; Fig. 1B). Aspirin administered at a dose of $40 \mathrm{ppm}$ produced a memory enhancing effect $(7.14 \pm 0.84 \mathrm{sec})$ from days $3-5$; indicating its effectiveness compared with the $\mathrm{AlCl}_{3}$-treated group $(\mathrm{P}<0.05)$, whilst doses of $160 \mathrm{ppm}$ were not as effective, compared with the $\mathrm{AlCl}_{3}$-treated group (Fig. 1B). During the test trial, which was performed on day 6 and involved the removal of the platform and recording of the time spent by the mouse within the platform quadrant, aspirin displayed a marked effect on spatial reference memory at doses of 40 and $160 \mathrm{ppm}(38.83 \pm 5.03$ and $36.82 \pm 5.51 \mathrm{sec}$, respectively), when compared with the $\mathrm{AlCl}_{3}$-treated group $(13.43 \pm 2.03 \mathrm{sec}$; $\mathrm{P}<0.001$; Fig. 1C).

Aspirin improves social affiliation and social novelty preference in mice. Aspirin was investigated for its effects on the sociability of mice by utilizing social interaction behavior. 
Table I. List of primers.

\begin{tabular}{llllr}
\hline Serial No. & Gene & \multicolumn{1}{c}{ Primer sequence (5' to 3') } & Ta & Cycles, n \\
\hline 1 & Pdyn & F, CAACCCCCTGATTTGCTCCC & 56 & 35 \\
2 & R, GCTGGTAAGGAGTCGGCTTT & 58 & 35 \\
3 & F, CCAATCAGCGATCTGGAGCTG & 56 & 35 \\
4 & Re, GATAACAGGGATGGCCGGAG & F, AAGCTCTCATTGAGGCACCC & 56 \\
5 & Re, TGCACGCCAGGAAATTGATG & F, TCGTCCGGTACACCAAATTGA & 54 & 32 \\
& Oprd1 & R, GGAAGTCCAGGGCTTTGACA & 55 & 35 \\
\hline
\end{tabular}

Ta, annealing temperature; Pdyn, prodynorphin; F, forward; R, reverse; Oprk1, opioid receptor, $\kappa$ 1; Penk, pre-proenkephalin; Oprd1, opioid receptor, $\delta 1$.

A

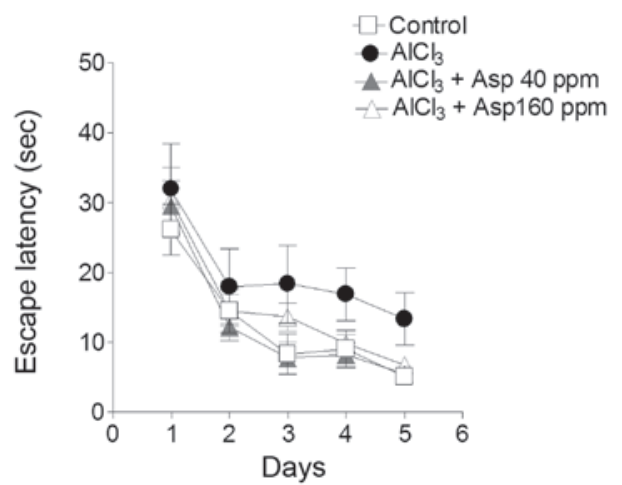

B
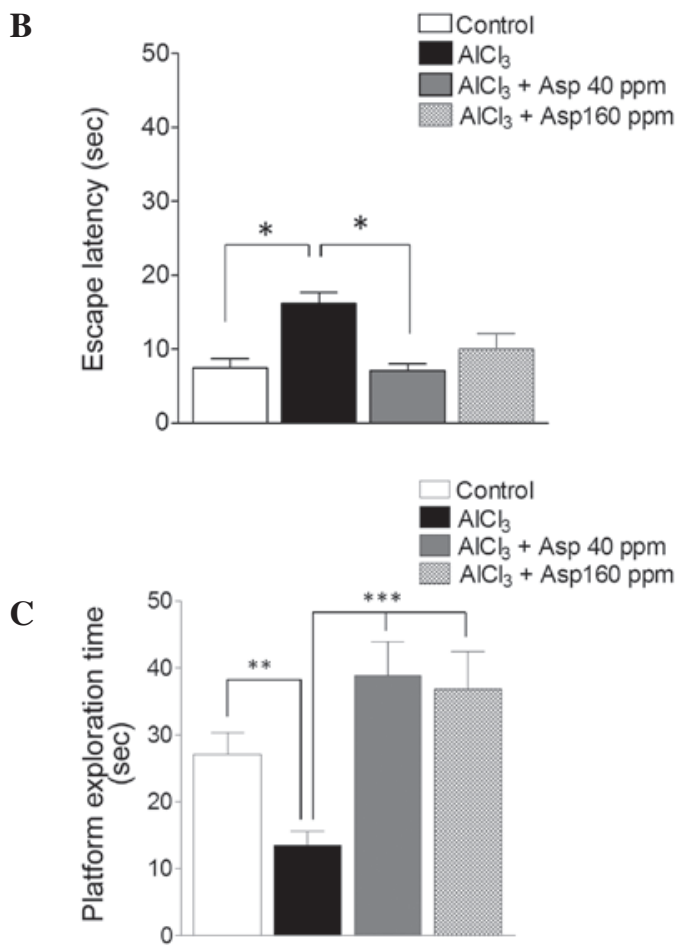

Figure 1. Spatial reference memory. Effects of Asp on memory as assessed by the Morris water maze test. (A) Spatial reference memory over 5 testing days. (B) Spatial reference memory on final 3 days. (C) Test trial on day 6. Data are presented as mean \pm standard error of the mean $(n=7-12) .{ }^{*} \mathrm{P}<0.05,{ }^{* *} \mathrm{P}<0.01$, ${ }^{* * *} \mathrm{P}<0.001$ (analysis of variance followed by Bonferroni's comparison test). Asp, aspirin.
$\mathrm{AlCl}_{3}$-treated mice displayed significantly reduced levels of interaction with mouse A $(9.38 \pm 3.33 \%)$ compared with the control group $(44.52 \pm 7.68 \%$; $\mathrm{P}<0.001)$. Following treatment with aspirin (40 and $160 \mathrm{ppm}$ ), there was a significant improvement in the sociability levels of the mice $(45.6 \pm 6.09$ and $35.72 \pm 9.38 \%$, respectively; $\mathrm{P}<0.001$ and $\mathrm{P}<0.01$, respectively; Fig. 2A) compared with the $\mathrm{AlCl}_{3}$-treated group.

The $\mathrm{AlCl}_{3}$-induced toxicity group failed to demonstrate social affiliation during session I, as is evident from the similar amount of time spent with mouse A $(9.38 \pm 3.33 \%)$ as with the empty cage $(8.65 \pm 3.19 \%)$. Conversely, the control group displayed significantly greater interaction levels with mouse A, compared with the empty cage $(44.52 \pm 7.68$ vs. $12.64 \pm 1.81 \%$ respectively; $\mathrm{P}<0.001$ ). Mice treated with aspirin at doses of 40 and $160 \mathrm{ppm}$ displayed significantly increased $(\mathrm{P}<0.001)$ interaction times with mouse A $(45.60 \pm 6.08$ and $35.72 \pm 9.38 \%$, respectively) compared with the empty cage $[14.17 \pm 2.78 \%$ $(\mathrm{P}<0.001)$ and $8.26 \pm 2.35 \%(\mathrm{P}<0.05)$, respectively; Fig. $2 \mathrm{~A})$.

$\mathrm{DI}$ in the $\mathrm{AlCl}_{3}$-treated group was significantly reduced in session I, compared with the control group $(0.46 \pm 0.13$ vs. $0.74 \pm 0.05$, respectively). At doses of 40 and $160 \mathrm{ppm}$ aspirin, an improvement in DI was observed $(0.75 \pm 0.04$ and $0.79 \pm 0.06$, respectively; Fig. $2 \mathrm{~B})$, when compared with the $\mathrm{AlCl}_{3}$-treated group $(0.46 \pm 0.13)$.

In session II, the empty cage was replaced with a new unfamiliar mouse (mouse B), and the mice were tested for social memory and social novelty preference. The $\mathrm{AlCl}_{3}$-treated group displayed significantly reduced interaction levels with mouse $\mathrm{B}$, compared with the control group (7.94 \pm 3.48 vs. $41.73 \pm 6.27 \%$, respectively; $\mathrm{P}<0.001)$. Following treatment with aspirin (40 and $160 \mathrm{ppm}$ ), social novelty preference was improved as compared with the $\mathrm{AlCl}_{3}$-treated group $(28.69 \pm 6.12$ and $37.01 \pm 6.89 \%$, respectively; $\mathrm{P}<0.01$ and $\mathrm{P}<0.001$; Fig. 2C).

$\mathrm{AlCl}_{3}$-treated mice failed to demonstrate a preference for social novelty and spent similar amounts of time with mouse A $(5.86 \pm 2.59 \%)$ and mouse B $(7.94 \pm 3.48 \%)$. This was in contrast to the control group, which displayed a significantly greater percent interaction time with mouse B $(41.73 \pm 6.27 \%)$ than with mouse A $(17.08 \pm 2.55 \% ; \mathrm{P}<0.01)$. Mice treated with 
A
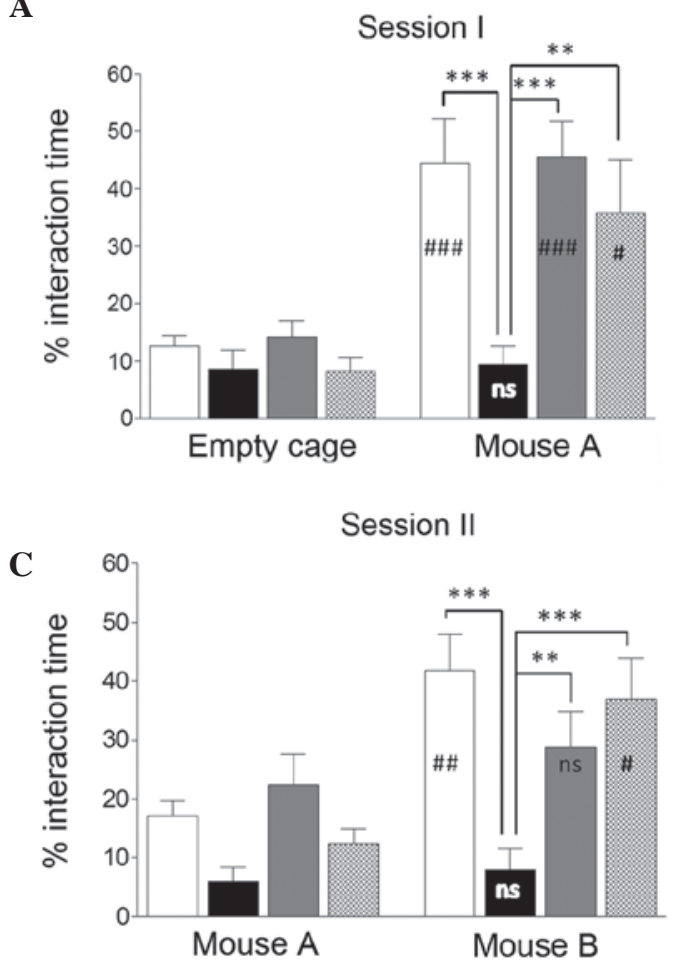

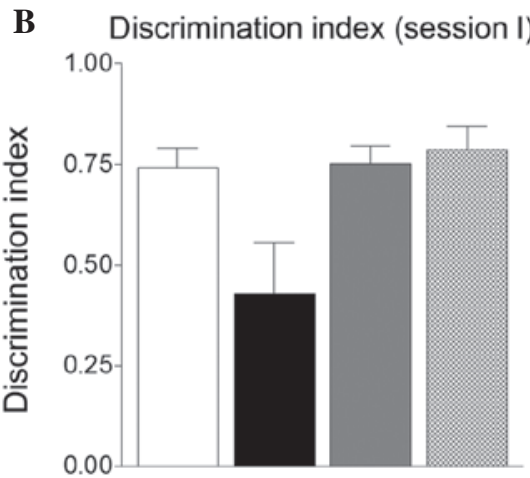

Discrimination index (session II)

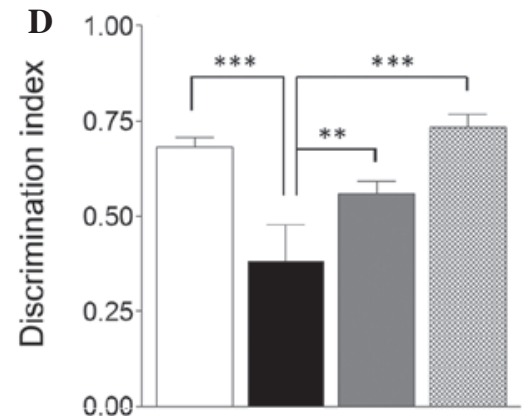

Figure 2. Effect of Asp on social interaction behavior. (A) Interaction time and (B) discrimination index during session I (social affiliation). (C) Interaction time and (D) discrimination index for session II (social novelty preference). Data are presented as mean \pm standard error of the mean ( $=5-9) .{ }^{* *} \mathrm{P}<0.01,{ }^{* * *} \mathrm{P}<0.001$ (analysis of variance followed by Bonferroni's comparison test). ${ }^{\#} \mathrm{P}<0.05,{ }^{\# \#} \mathrm{P}<0.01,{ }^{\# \#} \mathrm{P}<0.001$ vs. empty cage (session I) or mouse A (session II) (unpaired t-test). n.s., no significance; Asp, aspirin.

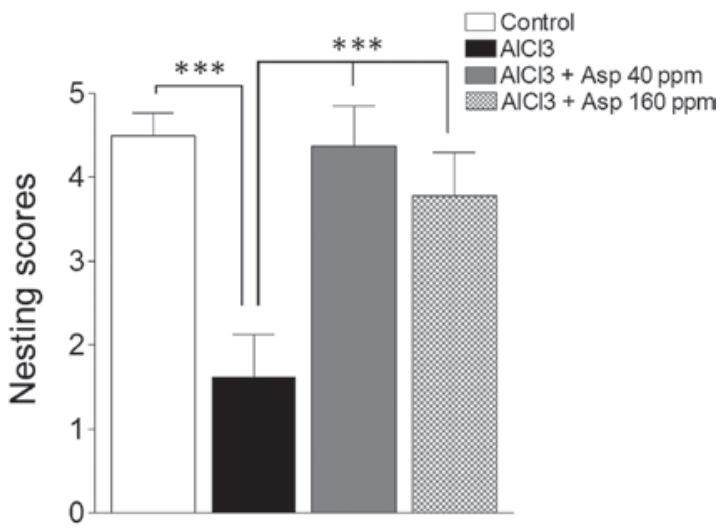

Figure 3. Effect of Asp on nesting behavior. Data are presented as mean \pm standard error of the mean $(n=7-8) .{ }^{* * * *} \mathrm{P}<0.001$ (analysis of variance followed by Bonferroni_s comparison test). Asp, aspirin.

a 40 ppm dose of aspirin did not display significantly different interaction levels with mouse B and mouse A $(28.69 \pm 6.12$ vs. 22.29 $\pm 5.26 \%$, respectively; Fig. 2C). However, when treated with a $160 \mathrm{ppm}$ dose of aspirin, mice showed significantly greater interaction levels with mouse B compared with mouse A (37.01 \pm 6.89 vs. $12.42 \pm 2.63$, respectively; $\mathrm{P}<0.05$; Fig. 2C), revealing the therapeutic effect of aspirin on social novelty preference at this dose.

The DI of the $\mathrm{AlCl}_{3}$-treated group was significantly reduced in session II, compared with the control group $(0.38 \pm 0.09$ vs. $0.68 \pm 0.02$, respectively; $\mathrm{P}<0.001)$. However, mice treated with aspirin doses of 40 and 160 ppm displayed a significant improvement in DI when compared with $\mathrm{AlCl}_{3}$-treated mice $[0.56 \pm 0.03(\mathrm{P}<0.01)$ and $0.73 \pm 0.03(\mathrm{P}<0.001)$, respectively; Fig. 2D].

Aspirin improves nesting behavior in mice. Aspirin was investigated for its role on nesting behavior. The $\mathrm{AlCl}_{3}$-treated group displayed a significant impairment in nest building behavior when compared with the control group $(1.63 \pm 0.49$ vs. $4.50 \pm 0.27$, respectively; $\mathrm{P}<0.001)$. However, treatment with aspirin (40 and $160 \mathrm{ppm}$ ) resulted in significant improvements in nesting scores $(4.37 \pm 0.49$ and $3.79 \pm 0.52$, respectively; $\mathrm{P}<0.001$; Fig. 3) when compared with the $\mathrm{AlCl}_{3}$-treated group.

Aspirin elevates contextual fear memory and enhances fear extinction learning in mice. Aspirin was investigated for its role on fear memory and fear extinction learning through fear conditioning, and contextual memory and fear extinction tests. During conditioning, all groups of mice displayed similar levels of freezing response, which was employed to measure levels of fear ( $\mathrm{P}>0.05$; Fig. 4A).

After $24 \mathrm{~h}$ of fear conditioning, mice were assessed for context-dependent fear memory. The $\mathrm{AlCl}_{3}$-treated group displayed significantly decreased levels of freezing $(1.49 \pm 0.62 \%)$ in the context compared with the control group $(26.81 \pm 7.92 \%$; $\mathrm{P}<0.05)$. Mice treated with aspirin displayed an elevated freezing response at doses of $40 \mathrm{ppm}$ (48.05 \pm 10.6 ; $\mathrm{P}<0.001)$ and $160 \mathrm{ppm}(27.25 \pm 8.06$; Fig. 4B) compared with the $\mathrm{AlCl}_{3}$-treated group.

Mice were then assessed for fear extinction learning. The control group and the aspirin-treated groups (40 and 160 ppm) 
A
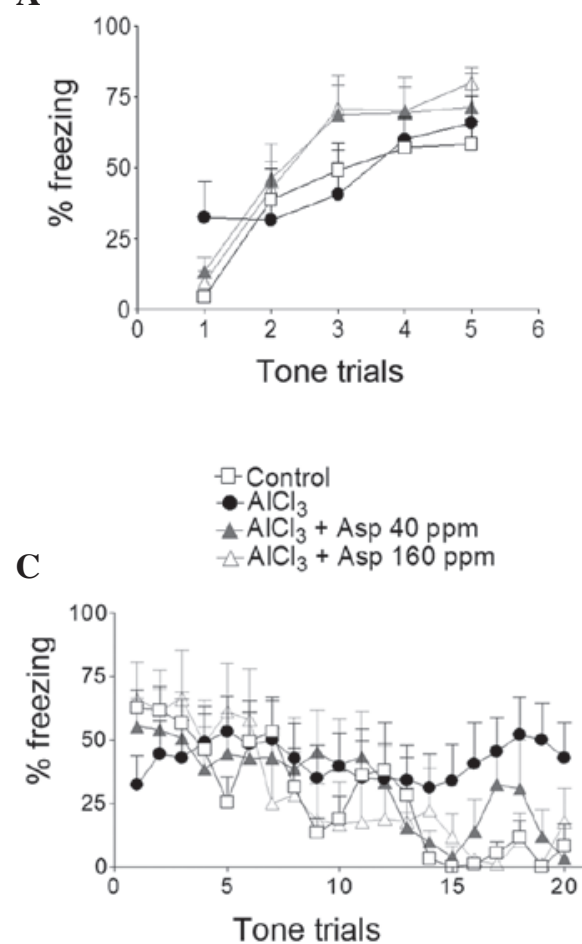

B

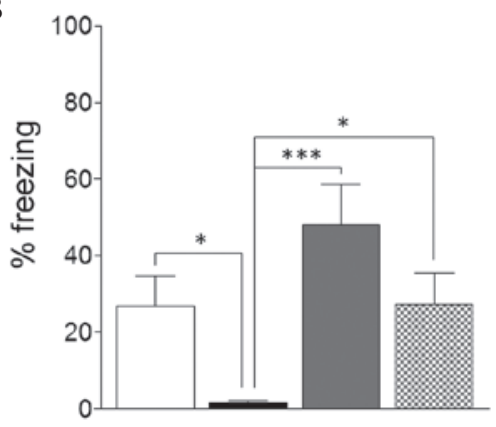

D

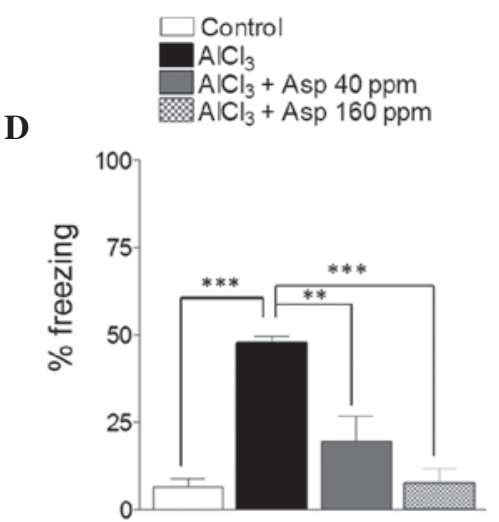

Figure 4. Effect of Asp on fear conditioning, contextual fear memory and fear extinction learning. (A) Fear conditioning test, with fear response plotted as \% freezing during the conditioned stimulus trial. (B) Context-dependent fear memory, plotted as \% freezing response. (C) Fear extinction learning over 20 trials. (D) Fear extinction learning in the final $4 \mathrm{CS}$ trials. Data are presented as mean \pm standard error of the mean $(\mathrm{n}=5-13)$. ${ }^{*} \mathrm{P}<0.05$, ${ }^{* *} \mathrm{P}<0.01$ and ${ }^{* * *} \mathrm{P}<0.001$ (analysis of variance followed by Bonferroni's comparison test). Asp, aspirin.

demonstrated reduced levels of freezing response after $20 \mathrm{CS}$ trials. By contrast, the $\mathrm{AlCl}_{3}$-treated group maintained high freezing response until the completion of the $20 \mathrm{CS}$ trials (Fig. 4C). In the final four tone trials, the $\mathrm{AlCl}_{3}$-treated group displayed a high percentage freezing level, indicating impaired fear extinction learning compared with the control group $(47.57 \pm 2.07$ vs. $6.383 \pm 2.47 \%$, respectively; $\mathrm{P}<0.001)$. The two doses of aspirin led to a reduction of the percent freezing $[19.59 \pm 7.16 \%(\mathrm{P}<0.01)$ and $7.63 \pm 4.04 \%(\mathrm{P}<0.001)$, respectively; Fig. 4D) in the final four tones trials, indicating enhanced fear extinction learning in aspirin-treated groups compared with the $\mathrm{AlCl}_{3}$-treated group.

Aspirin does not affect Penk expression. Within the cortex, increased mRNA expression levels of Penk were observed in the $\mathrm{AlCl}_{3}$-treated group compared with the control group; however, the difference was not significant $(1.71 \pm 1.10$ vs. $0.42 \pm 0.05$, respectively; $\mathrm{P}>0.05$ ). The levels of Penk in mice treated with 40 and $160 \mathrm{ppm}$ aspirin were not significantly different when compared with the $\mathrm{AlCl}_{3}$-treated group $(0.79 \pm 0.09$ and $0.62 \pm 0.14$, respectively; $\mathrm{P}>0.05$; Fig. $5 \mathrm{~A})$.

Within the hippocampus, no significant differences in the levels of Penk were observed in $\mathrm{AlCl}_{3}$-treated mice compared with the control group. Following treatment with aspirin at both doses, expression levels remained unchanged (Fig. 5B).

Aspirin decreases Pdyn expression in the cortex. Within the cortex, Pdyn expression levels were significantly elevated in the $\mathrm{AlCl}_{3}$-treated group compared with the control group $(1.95 \pm 0.84$ vs. $0.49 \pm 0.08$, respectively; $\mathrm{P}<0.05)$. Treatment with aspirin resulted in a decrease in Pdyn expression levels at the $40 \mathrm{ppm}$ dose compared with the $\mathrm{AlCl}_{3}$-treated group $(0.57 \pm 0.20$ vs. $1.95 \pm 0.84 ; \mathrm{P}<0.05)$; however, at the $160 \mathrm{ppm}$ dose, no significant effect was observed (Fig. 6A).

In the hippocampus, despite a general trend depicting an increase in Pdyn expression levels, there was no significant difference in Pdyn expression levels in the $\mathrm{AlCl}_{3}$-treated group compared with the control group $(2.50 \pm 1.53$ vs. $1.13 \pm 0.34$, respectively; Fig. 6B). Furthermore, Pdyn expression levels in mice treated with aspirin doses of 40 and $160 \mathrm{ppm}$ were not significantly different $(0.90 \pm 0.11$ and $1.01 \pm 0.16$, respectively)

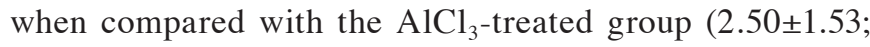
Fig. 6B).

Aspirin decreases $\delta$ opioid receptor (DOR) expression in the cortex. Within the cortex, DOR expression levels were significantly elevated in the $\mathrm{AlCl}_{3}$-treated group compared with the control group $(3.69 \pm 1.43$ vs. $0.86 \pm 0.10$; Fig. 7A). Treatment with aspirin resulted in a significant decrease in DOR expression levels at doses of $40(1.09 \pm 0.08)$ and $(1.27 \pm 0.08) 160 \mathrm{ppm}$ compared with the $\mathrm{AlCl}_{3}$-treated group $(3.69 \pm 1.43 ; \mathrm{P}<0.05$; Fig. 7A).

Within the hippocampus, no significant differences in DOR expression levels were observable in the $\mathrm{AlCl}_{3}$-treated group compared with the control group $(2.76 \pm 1.41$ vs. 1.04 \pm 0.33 ; Fig. 7B). Furthermore, DOR expression levels in the mice treated with aspirin doses of $40(1.41 \pm 0.13)$ and $160 \mathrm{ppm}(1.49 \pm 0.32)$ were not significantly different when compared with the $\mathrm{AlCl}_{3}$-treated group (3.69 $\pm 1.43 ; \mathrm{P}<0.05$; Fig. 7B). 
A

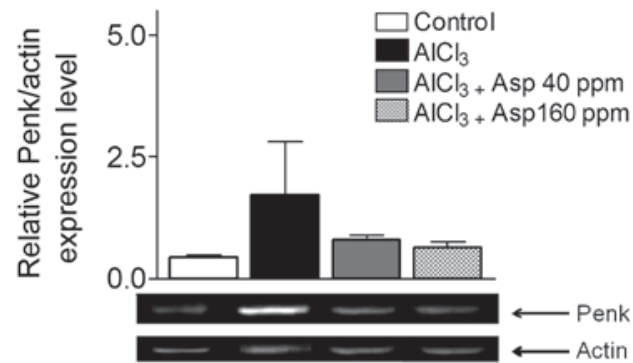

B

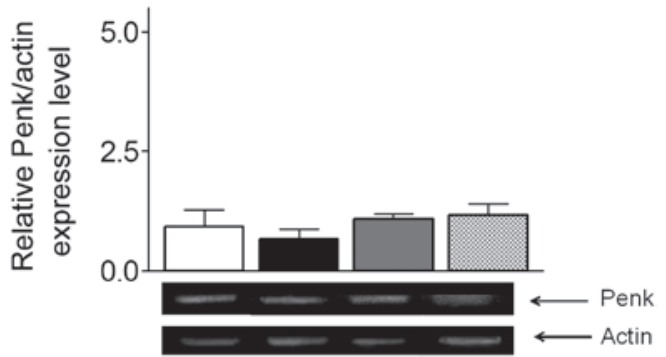

Figure 5. Effect of aspirin on Penk mRNA expression levels in the (A) cortex and (B) hippocampus, normalized with actin. Representative reverse transcription-polymerase chain reaction gels are displayed, and arrows indicate desired product and actin bands from cortex and hippocampus. Data are presented as mean \pm standard error of the mean $(n=4-8)$. Analysis of variance followed by Bonferroni's comparison test. Penk, proenkephalin; Asp, aspirin.

A

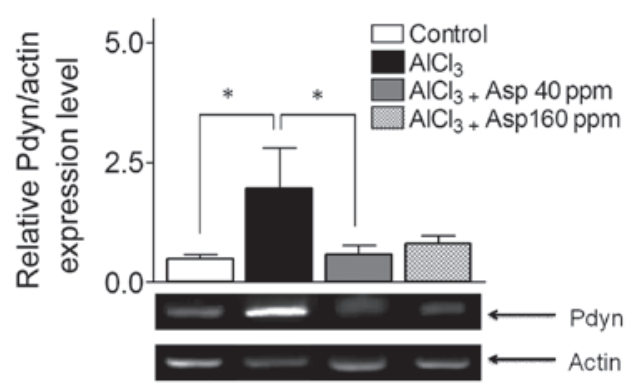

B

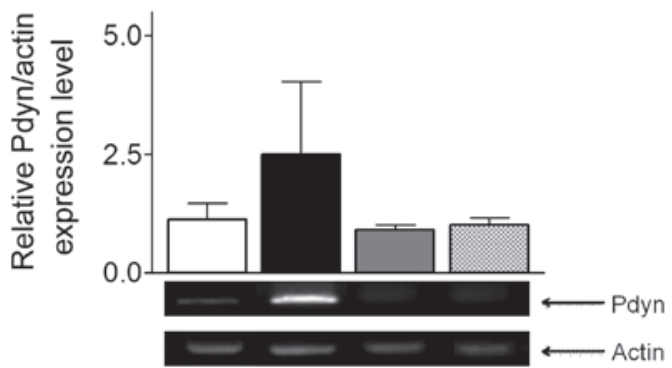

Figure 6. Effect of aspirin on Pdyn mRNA expression levels in the (A) cortex and (B) hippocampus normalized with actin. Representative reverse transcription-polymerase chain reaction gels are displayed and arrows indicate the desired product and actin bands from the cortex and hippocampus. Data are presented as mean \pm standard error of the mean $(n=4-5)$. . $\mathrm{P}<0.05$ (analysis of variance followed by Bonferroni's comparison test). Pdyn, prodynorphins; Asp, aspirin

Aspirin does not affect KOR expression. Within the cortex, no significant differences in KOR expression levels were observed in the $\mathrm{AlCl}_{3}$-treated group compared with the control and aspirin-treated groups at both doses ( $\mathrm{P}>0.05$; Fig. 8A).

Similarly, within the hippocampus, no significant difference in KOR expression levels were observed in the $\mathrm{AlCl}_{3}$-treated group $(1.59 \pm 1.02)$ compared with the control
A

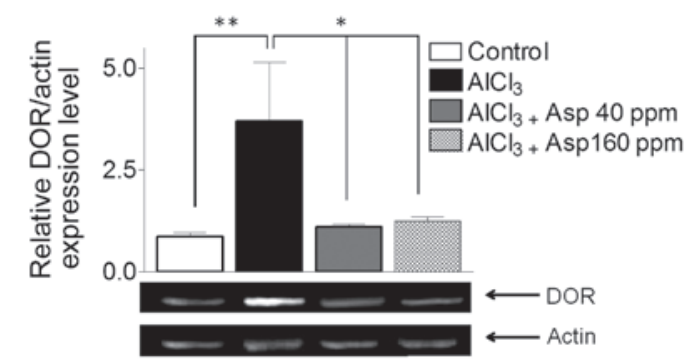

B

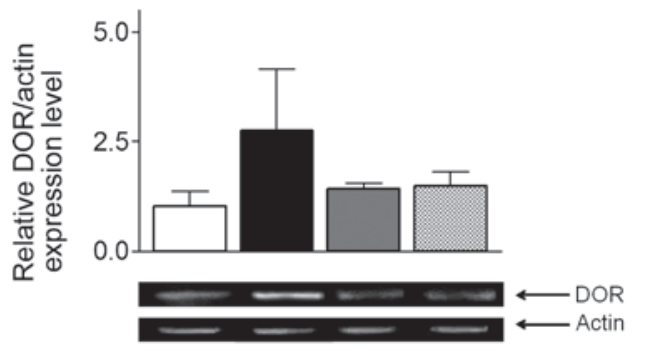

Figure 7. Effect of aspirin on DOR mRNA expression levels in the (A) cortex and (B) hippocampus, normalized with actin. Representative reverse transcription-polymerase chain reaction gels are displayed with arrows indicating desired product and actin bands from cortex and hippocampus. Data are presented as mean \pm standard error of the mean $(n=4-8) .{ }^{*} \mathrm{P}<0.05$, ${ }^{* *} \mathrm{P}<0.01$ (analysis of variance followed by Bonferroni's comparison test). DOR, $\delta$ opioid receptor; Asp, aspirin.

A

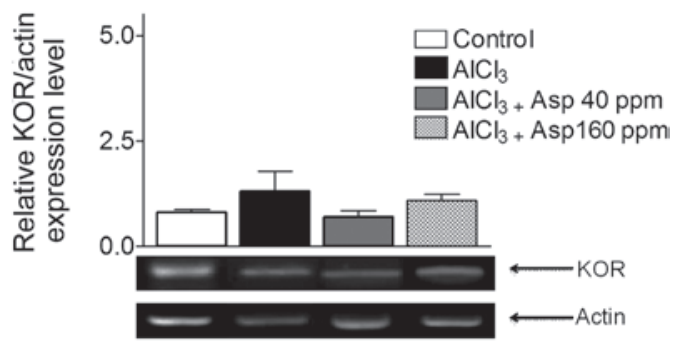

B

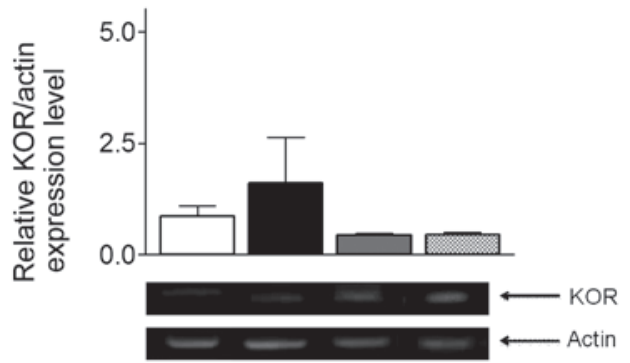

Figure 8. Effect of aspirin on KOR mRNA expression levels in (A) the cortex and (B) hippocampus normalized with actin. Analysis of variance followed by Bonferroni's comparison test were performed. Representative reverse transcription-polymerase chain reaction gels are displayed with arrows indicate desired product and actin bands from cortex and hippocampus. Data are presented as mean \pm standard error of the mean $(n=4-5)$. Analysis of variance followed by Bonferroni_s comparison test. KOR, $\kappa$ opioid receptor; Asp, aspirin.

group $(0.86 \pm 0.23)$ or 40 and $160 \mathrm{ppm}$ aspirin-treated groups $(0.44 \pm 0.03$ and $0.45 \pm 0.06$; $P>0.05$; Fig. $8 \mathrm{~B})$.

\section{Discussion}

Aspirin is an anti-inflammatory drug that is known to reduce the synthesis of prostaglandin through the inhibition of COXs (38). Aspirin has multiple therapeutic targets, including 
COD enzymes and acid-sensing ion channels (39-41). As a result the present study aimed to assess the performance of aspirin against novel peptide targets, including Pdyn, Penk and their respective receptors, KOR and DOR. The opioid system is known for its role in neurodegeneration, cognitive impairment, behavioral dysfunction, amyloid $\beta$ production and the hyperphosphorylation of $\tau$ proteins $(42,43)$.

The hippocampus and cortex are regions of the brain that are vital for learning and memory, and are highly susceptible to damage in the early stages of neuropathology (44). The Morris water maze is typically employed to asses hippocampus- and cortex-dependent learning (34). Elevated expression levels of dynorphin and enkephalin within the hippocampus interfere with spatial learning and memory, and the effect is mediated by opioid receptors within the dorsal hippocampus (45). Through the results of the Morris water maze experiment, the present study revealed that mice treated with aspirin displayed improvements in learning, which is in accordance with observations made in a prior study (46). In the present study, mice treated with aspirin $(40 \mathrm{ppm})$ displayed enhanced levels of learning during the final 3 days of assessment. A potential mechanism by which aspirin improved cognitive impairment may be a result of the downregulation of Pdyn and DOR expression levels in the cortex. The present study observed that a 40 ppm dose of aspirin was more beneficial than a 160 ppm dose in the Morris water maze test. In accordance with previous studies $(46,47)$, the present study revealed a significant distinction in certain aspects of cognitive performance for mice treated with aspirin, compared with an $\mathrm{AlCl}_{3}$-treated group.

Social interaction behaviors are dependent on the hippocampus and cortex regions of the brain (48). KOR agonists were previously revealed to suppress all measures of social play in juvenile mice (49), confirming the inhibitory effects of elevated expression levels of dynorphin on the social behavior of mice. The present study revealed that aspirin-treated mice presented with significantly greater sociability levels when compared with the $\mathrm{AlCl}_{3}$-treated group. In addition, aspirin-treated mice displayed improved results in social novelty preference at both doses of aspirin administered (40 and $160 \mathrm{ppm}$ ) and the underlying mechanism may involve a reduction in dynorphin expression levels. However, further investigation is required to consolidate upon this hypothesis. These data suggest the potential of aspirin in cognition, as well as social behavior.

Mice construct nests for the purpose of thermoregulation and reproduction. Nesting behavior in mice indicates the integrity of the hippocampus and the cortex (35). Mice with lesioned hippocampi did not exceed a score of 3 in the nest scoring system in the present study, whilst scores of 4 or 5 indicated a high quality nest and, hence, a healthy hippocampus. Aspirin-treated mice displayed improved nesting scores with either of the two doses administered. Nest construction is a natural, species-typical behavior in rodents (50) and may be considered analogous to the 'activities of daily living'. Thus, the present study provides evidence to suggest that aspirin has the ability to improve non-cognitive behaviors or the activities of daily living in neurodegenerative patients.

The parts of the brain involved in fear memory, including fear acquisition, contextual fear and fear extinction, are the amygdala, hippocampus, cortex and prefrontal cortex $(51,52)$. Mice treated with aspirin (40 and 160 ppm) displayed improved fear acquisition levels during fear conditioning sessions, enhanced contextual fear memory levels and improved extinction learning compared with the $\mathrm{AlCl}_{3}$-treated mice. This exemplifies a novel role for aspirin in improving hippocampus and amygdala-dependent learning, and extending the therapeutic potential of aspirin in neurodegenerative diseases.

Endogenous dynorphin is involved in learning and memory through the inhibition of presynaptic glutamate release via KOR and modulation of its long-term potentiation (LTP), as a retrograde inhibitory neurotransmitter (53). Cognitive and behavioral deficits arise as a result of enkephalin upregulation and DOR alteration in neurodegeneration (53). It therefore follows that a cause of cognitive decline in neurodegeneration is elevated levels of dynorphins and enkephalins $(45,54)$. The data presented in the current study concerning the expression levels of opioid system genes (Penk, Pdyn and their respective receptors, DOR and KOR), revealed that aspirin treatment decreased the expression levels of opioid system genes, which may be one of several mechanisms through which aspirin restores features damaged by cognitive impairment. The results of the current study demonstrated that the opioid system is partially affected by aspirin, as was evident by the absence of differences in hippocampal expression levels of opioid system genes (Penk, Pdyn, KOR and DOR) among the three groups (control, $\mathrm{AlCl}_{3}$-treated and aspirin-treated). Within the cortex, aspirin displayed a dose-specific effect, with only the $40 \mathrm{ppm}$ dose of aspirin causing a reduction in the expression levels of Pdyn. The expression levels of DOR were affected at both doses of aspirin; however, no significant change in Penk or KOR expression levels were observed; rather, only a general trend toward decreased expression was observed. The hippocampus and cortex are equally important in neurodegenerative disorders, however, acetylcholine release (which is involved in the pathology of AD) has a greater effect on opiate agonists in the cortex in the brains of rats compared with the hippocampus, where opiate agonists display a dose-dependent effect on acetylcholine release (55). Considering the acetylcholine hypothesis concerning AD (56), we hypothesize that the opioid system will have marked effects on neurodegeneration and AD pathogenesis within the cortex through the reduction of acetylcholine release. Furthermore, the present study revealed that aspirin was more effective within the cortex, although the mechanism regarding its effect here remains unknown. In the cortex, aspirin significantly decreased the expression levels of Pdyn and DOR genes; this was accompanied by improvements in cognitive and non-cognitive behaviors. Another possible association between aspirin and dynorphin may be LTP, as aspirin is hypothesized to reverse LTP impairments (57) that occur as a result of elevated levels of dynorphin (53), thereby improving learning and memory.

Additionally, aspirin is known to improve cognitive decline in neurodegenerative disorders through multiple mechanisms (58-60) and, at higher doses, attenuation of inflammatory processes through the inhibition of COXs. The exact mechanism of action of aspirin within various disorders, including $\mathrm{AD}$, remains relevant and requires further exploration. 
In conclusion, aspirin improved learning, memory, social behavior and non-cognitive behavior in mice by decreasing Pdyn and DOR expression, suggesting its therapeutic potential as multitarget drug for AD. Further studies are required to assess long term effects and benefits of aspirin in AD.

\section{Acknowledgements}

The present authors thank the Atta-ur-Rahman School of Applied Biosciences, National University of Sciences and Technology (Islamabad, Pakistan) for providing funding, support and research facilities.

\section{References}

1. Prince M, Bryce R, Albanese E, Wimo A, Ribeiro W and Ferri CP: The global prevalence of dementia: A systematic review and metaanalysis. Alzheimers Dement 9: 63-75 e62, 2013.

2. Pohl HR, Roney $\mathrm{N}$ and Abadin HG: Metal ions affecting the neurological system. Met Ions Life Sci 8: 247-262, 2011.

3. Suárez-Fernández MB, Soldado AB, Sanz-Medel A, Vega JA, Novelli A and Fernández-Sánchez MT: Aluminum-induced degeneration of astrocytes occurs via apoptosis and results in neuronal death. Brain Res 835: 125-136, 1999.

4. Platt B, Fiddler G, Riedel G and Henderson Z: Aluminium toxicity in the rat brain: Histochemical and immunocytochemical evidence. Brain Res Bull 55: 257-267, 2001.

5. Chen J, Wang M, Ruan D and She J: Early chronic aluminium exposure impairs long-term potentiation and depression to the rat dentate gyrus in vivo. Neuroscience 112: 879-887, 2002.

6. Walton JR: Chronic aluminum intake causes Alzheimer's disease: Applying Sir Austin Bradford Hill's causality criteria. Alzheimer's Dis 40: 765-838, 2014.

7. Bondy SC: The neurotoxicity of environmental aluminum is still an issue. Neurotoxicology 31: 575-581, 2010.

8. Andrási E, Páli N, Molnár Z and Kösel S: Brain aluminum, magnesium and phosphorus contents of control and Alzheimer-diseased patients. J Alzheimers Dis 7: 273-284, 2005.

9. Voilley N, de Weille J, Mamet J and Lazdunski M: Nonsteroid anti-inflammatory drugs inhibit both the activity and the inflammation-induced expression of acid-sensing ion channels in nociceptors. J Neurosci 21: 8026-8033, 2001.

10. McGeer EG and McGeer PL: The importance of inflammatory mechanisms in Alzheimer disease. Exp Gerontol 33: 371-378, 1998

11. Stewart WF, Kawas C, Corrada M and Metter EJ: Risk of Alzheimer's disease and duration of NSAID use. Neurology 48: 626-632, 1997.

12. Molnar FJ, Man-Son-Hing M, St John P, Brymer C, Rockwood K and Hachinski V: Subcortical vascular dementia: Survey of treatment patterns and research considerations. Can J Neurol Sci 25: 320-324, 1998 .

13. Dennis M and Boyle A: Management of cognitive impairment of vascular origin. Psychiatri Bull 22: 285-287, 1998.

14. Hirohata M, Ono K, Naiki $\mathrm{H}$ and Yamada M: Non-steroidal anti-inflammatory drugs have anti-amyloidogenic effects for Alzheimer's beta-amyloid fibrils in vitro. Neuropharmacology 49: 1088-1099, 2005.

15. Medeiros R, Kitazawa M, Passos GF, Baglietto-Vargas D, Cheng D, Cribbs DH and LaFerla FM: Aspirin-triggered lipoxin A4 stimulates alternative activation of microglia and reduces Alzheimer disease-like pathology in mice. Am J Pathol 182: 1780-1789, 2013.

16. Conason AH and Sher L: Alcohol use in adolescents with eating disorders. Int J Adolesc Med Health 18: 31-36, 2006

17. Melzack R: From the gate to the neuromatrix. Pain 6 (Suppl 6) S121-S126, 1999.

18. Snyder SH and Childers SR: Opiate receptors and opioid peptides. Annu Rev Neurosci 2: 35-64, 1979.

19. Blackburn TP, Cross AJ, Hille C and Slater P: Autoradiographic localization of delta opiate receptors in rat and human brain. Neuroscience 27: 497-506, 1988.

20. Hiller JM, Itzhak Y and Simon EJ: Selective changes in mu, delta and kappa opioid receptor binding in certain limbic regions of the brain in Alzheimer's disease patients. Brain Res 406: 17-23, 1987.
21. Alfaras-Melainis K, Gomes I, Rozenfeld R, Zachariou V and Devi L: Modulation of opioid receptor function by protein-protein interactions. Front Biosci (Landmark Ed) 14: 3594-3607, 2009.

22. Simonds WF: The molecular basis of opioid receptor function. Endocr Rev 9: 200-212, 1988.

23. Kuzmin A, Madjid N, Terenius L, Ogren SO and Bakalkin G: Big dynorphin, a prodynorphin-derived peptide produces NMDA receptor-mediated effects on memory, anxiolytic-like and locomotor behavior in mice. Neuropsychopharmacology 31 : 1928-1937, 2006.

24. Sandin J, Nylander I, Georgieva J, Schött PA, Ogren SO and Terenius L: Hippocampal dynorphin B injections impair spatial learning in rats: A kappa-opioid receptor-mediated effect. Neuroscience 85: 375-382, 1998.

25. Ukai M, Itoh J, Kobayashi T, Shinkai N and Kameyama T: Effects of the kappa-opioid dynorphin A(1-13) on learning and memory in mice. Behav Brain Res 83: 169-172, 1997.

26. Gallagher M, King RA and Young NB: Opiate antagonists improve spatial memory. Science 221: 975-976, 1983.

27. Derrick BE, Rodriguez SB, Lieberman DN and Martinez JL Jr: $\mathrm{Mu}$ opioid receptors are associated with the induction of hippocampal mossy fiber long-term potentiation. J Pharmacol Exp Ther 263: 725-733, 1992.

28. Nieto MM, Guen SL, Kieffer BL, Roques BP and Noble F: Physiological control of emotion-related behaviors by endogenous enkephalins involves essentially the delta opioid receptors. Neuroscience 135: 305-313, 2005.

29. Jiang HK, Owyang VV, Hong JS and Gallagher M: Elevated dynorphin in the hippocampal formation of aged rats: Relation to cognitive impairment on a spatial learning task. Proc Natl Acad Sci USA 86: 2948-2951, 1989.

30. Davis KL, Mohs RC, Marin DB,Purohit DP, Perl DP, Lantz M, Austin G and Haroutunian V: Neuropeptide abnormalities in patients with early Alzheimer disease. Arch Gen Psychiatry 56: 981-987, 1999.

31. Saito T, Iwata N, Tsubuki S,Takaki Y, Takano J, Huang SM, Suemoto T, Higuchi M and Saido TC: Somatostatin regulates brain amyloid beta peptide Abeta42 through modulation of proteolytic degradation. Nat Med 11: 434-439, 2005.

32. National Research Council (US) Committee for the Update of the Guide for the Care and Use of Laboratory Animals: Guide for the Care and Use of Laboratory Animals. 8th edition. National Academic Press, Washington, 2011.

33. Hashmi AN, Yaqinuddin A and Ahmed T: Pharmacological effects of Ibuprofen on learning and memory, muscarinic receptors gene expression and APP isoforms level in pre-frontal cortex of $\mathrm{AlCl}_{3}$-induced toxicity mouse model. Int J Neurosci 125: 277-287, 2015.

34. Ahmed T, Enam SA and Gilani AH: Curcuminoids enhance memory in an amyloid-infused rat model of Alzheimer's disease. Neuroscience 169: 1296-1306, 2010.

35. Deacon R: Assessing burrowing, nest construction, and hoarding in mice. J Vis Exp e2607, 2012.

36. Lee S, Ahmed T, Lee S, Kim H, Choi S, Kim DS, Kim SJ, Cho J and Shin HS: Bidirectional modulation of fear extinction by mediodorsal thalamic firing in mice. Nat Neurosci 15: 308-314, 2012.

37. Ahmed T and Gilani AH: A comparative study of curcuminoids to measure their effect on inflammatory and apoptotic gene expression in an $\mathrm{A} \beta$ plus ibotenic acid-infused rat model of Alzheimer's disease. Brain Res 1400: 1-18, 2011.

38. Amann R and Peskar BA: Anti-inflammatory effects of aspirin and sodium salicylate. Eur J Pharmacol 447: 1-9, 2002.

39. Fink $M$ and Irwin P: Central nervous system effects of aspirin. Clin Pharmacol Ther 32: 362-365, 1982.

40. Bhatt LK and Addepalli V: Potentiation of aspirin-induced cerebroprotection by minocycline: A therapeutic approach to attenuate exacerbation of transient focal cerebral ischaemia. Diab Vasc Dis Res 9: 25-34, 2012.

41. Wang W, Ye SD, Zhou KQ, Wu LM and Huang YN: High doses of salicylate and aspirin are inhibitory on acid-sensing ion channels and protective against acidosis-induced neuronal injury in the rat cortical neuron. J Neurosci Res 90: 267-277, 2012.

42. Anthony IC, Norrby KE, Dingwall T, Carnie FW, Millar T, Arango JC, Robertson R and Bell JE: Predisposition to accelerated Alzheimer-related changes in the brains of human immunodeficiency virus negative opiate abusers. Brain 133: 3685-3698, 2010.

43. Lengauer E: Drug dependent adolescents have Alzheimer disease-like brains. Kinderkrankenschwester 26: 37, 2007 (In German) 
44. $\mathrm{Mu} \mathrm{Y}$ and Gage FH: Adult hippocampal neurogenesis and its role in Alzheimer's disease. Mol Neurodegener 6: 85, 2011.

45. McDaniel KL, Mundy WR and Tilson HA: Microinjection of dynorphin into the hippocampus impairs spatial learning in rats. Pharmacol Biochem Behav 35: 429-435, 1990.

46. Smith JW, Al-Khamees O, Costall B, Naylor RJ and Smythe JW: Chronic aspirin ingestion improves spatial learning in adult and aged rats. Pharmacol Biochem Behav 71: 233-238, 2002.

47. Breitner JC: The role of anti-inflammatory drugs in the prevention and treatment of Alzheimer's disease. Annu Rev Med 47: 401-411, 1996

48. Beer JS, John OP, Scabini D and KnightRT: Orbitofrontal cortex and social behavior: Integrating self-monitoring and emotion-cognition interactions. J Cogn Neurosci 18: 871-879, 2006.

49. Vanderschuren LJ, Niesink RJ, Spruijt BM and Van Ree JM: Muand kappa-opioid receptor-mediated opioid effects on social play in juvenile rats. Eur J Pharmacol 276: 257-266, 1995.

50. Deacon RM: Assessing nest building in mice. Nat Protoc 1 : 1117-1119, 2006.

51. Einarsson EO and Nader K: Involvement of the anterior cingulate cortex in formation, consolidation, and reconsolidation of recent and remote contextual fear memory. Learn Mem 19: 449-452, 2012.

52. Frankland PW, Bontempi B, Talton LE, Kaczmarek L and Silva AJ: The involvement of the anterior cingulate cortex in remote contextual fear memory. Science 304: 881-883, 2004
53. Wagner JJ, Terman GW and Chavkin C: Endogenous dynorphins inhibit excitatory neurotransmission and block LTP induction in the hippocampus. Nature 363: 451-454, 1993.

54. Meilandt WJ, Yu GQ, Chin J, Roberson ED, Palop JJ, Wu T, Scearce-Levie K and Mucke L: Enkephalin elevations contribute to neuronal and behavioral impairments in a transgenic mouse model of Alzheimer's disease. J Neurosci 28: 5007-5017, 2008.

55. Lapchak PA, Araujo DM and Collier B: Regulation of endogenous acetylcholine release from mammalian brain slices by opiate receptors: Hippocampus, striatum and cerebral cortex of guinea-pig and rat. Neuroscience 31: 313-325, 1989.

56. Muir JL: Acetylcholine, aging, and Alzheimer's disease. Pharmacol Biochem Behav 56: 687-696, 1997.

57. Hein AM and O'Banion MK: Neuroinflammation and memory: The role of prostaglandins. Mol Neurobiol 40: 15-32, 2009.

58. Thomas T, Nadackal TG and Thomas K: Aspirin and non-steroidal anti-inflammatory drugs inhibit amyloid-beta aggregation. Neuroreport 12: 3263-3267, 2001.

59. Harris JR: In vitro fibrillogenesis of the amyloid beta 1-42 peptide: Cholesterol potentiation and aspirin inhibition. Micron 33: 609-626, 2002.

60. Tortosa E, Avila J and Pérez M: Acetylsalicylic acid decreases tau phosphorylation at serine 422. Neurosci Lett 396: 77-80, 2006. 